\title{
CIGARETTE SMOKING AND HABITS (2): SOME STUDIES ON PERCEPTION AND PROMOTING FACTORS AMONG UNIVERSITY STUDENTS
}

\author{
U. Okpala \\ Lloyds Pharmacy, \\ Stretfield Hse., Alvescot Road, Carterton \\ Oxford OX18 $3 X Z$.
}

\begin{abstract}
A survey using structured questionnaire was carried out among 100 randomly picked second year classes of business students of University of Brighton approved by a University of Brighton Ethical Committee. It was tested for reliability to ensure consistency using the Test Re-test method. Out of 100 students, 47 were male and 53 female. Also, from the same 100, 51 were non-smokers, 29 were smokers, and 20, ex-smokers. Total of respondents $(Y=7, N=93)$ indicates that inhaling other peoples' smoke was not enjoyable so there is a general dislike. The major overall reason for liking smoking is because of its relaxation properties (mean=2.57). The main reason for starting smoking were friends smoked ascribed to 'cool' and curiosity reason, though majority did not agree to this. Few subjects agreed that they started smoking because their parent smoked, had money to buy cigarettes and their girlfriend or boyfriend smoked. Two-way Analysis of Variance (ANOVA) gave no significant difference between males and females, smokers and ex-smokers and no significant interaction between gender and being a smoker/ex-smoker. Students know that smoking is, very bad and dangerous to their health. They do know that stopping smoking will improve their health, but once they are hooked on it, it is very hard to quit.
\end{abstract}

Keywords: Smoking, Cigarette, Smokers, Nonsmokers, Ex-smokers.

\section{INTRODUCTION}

Tobacco is a sweet smelling product of aromatic leaves of Nicotiana family of plants. These leaves are dried and processed into cigarettes, cigars, and other forms. When lit and the smoke inhaled, it produces a pleasant sensation. Smoking is a popular recreational activity that accom- panies drinking alcohol and socializing and it is used to relieve stress, especially in women (Marsh and Mathieson, 1983). Some individuals perceive smoking to be glamorous and attractive. The strong desire for a particular body image and prevention of weight gain are often cited as reasons why young girls take up smoking (Okpala, 2003).

When smokers and non-smokers share the same 
rooms, non-smokers cannot avoid inhaling some of the smokers' tobacco smoke. This is passive smoking ...breathing in other people's smoke. It is dangerous and also kills, causing lung cancer in non-smokers (Dept. Health, 1998; www.ess. gov.je/his/brochures/passive_smoking/default. asp?URL=what is PS,html).

Smoking is a very easy habit to pick up. A number of Studies have been done on student smoking. A study investigated the smoking habits of King Saud University students in Abha, Saudi Arabia. The aim was to estimate the prevalence of smoking to determine ecological factors for the problem, and to assess the students' knowledge about the health effects of smoking, and attitudes towards public action against smoking. This involved 202 medical students at the University College of Medicine and 202 students at the College of Education. The students were subjected to a modified Arabic version of the World Health Organisation standard questionnaire for young people, to study their knowledge, attitudes, and practices of smoking. This study found out that even though students of the Abha branch of King Saud University have sound knowledge of the harmful effects of smoking, and a generally favourable attitude towards public measures against the habit, smoking still constitutes a sizeable problem among them, possibly due to the addictive effect of nicotine, peer pressure, negative parental attitudes and other factors (www.kfshrc.edu.sa/ annals/183/97-279.html).

An earlier work of gender and smoking patterns among University of Brighton Business Students' showed the prevalence and trend of smoking among age groups, ethnicity, religion, and nationality (Okpala, 2006). This work is a follow-up study of university students' attitudes, views and perspective on smoking in England, which reveals the perception and prompting factors among randomly picked second year business students.

\section{MATERIALS AND METHODS}

A survey was carried out at Mithras House among 100 students, randomly picked from two classes of the second year of University of Brighton. This is because they have socialized in the university for almost two years. Brighton is a cosmopolitan community with excellent university that attracts a lot of students from home and abroad. The population under study was business students. It included those who smoke have smoked before and never smoked.

Instrument for data collection was structured questionnaire approved by the University of Brighton Ethical Committee. It was tested for reliability to ensure its consistency using the Test Re-test method.

First five questionnaire responses "were correlated using Pearson's Product Moment Correlation (PPMC) with Micros ft Excel Package. Normally, correlation coefficient values range from -1 through 0 to +1 (Middleton, 2004). Correlation coefficient values for reliability of the questionnaire were $0.9861,0.9534,1.0000$, 0.9608 and 1.0000 . These correlation values which range from 0.9534 to 1.0000 were very high, hence consistent and reliable.

Questionnaires were administered, waited upon to be filled by respondents and collected as soon as completed, on the same day. Data were analyzed statistically using percentages, means, ttests, one-way and two-way ANOVA (Analysis of Variance).

\section{RESULTS}

From the 100 students investigated, smokers, exsmokers and non-smokers views on 'inhalation of other people's smoke' indicated Yes (Y) or No $(N)$ as follows: Smokers (Male: $Y=1, N=1$ 1; Female: $Y=4, N=11$ ), Ex-smokers (Male: $Y=0$, $\mathrm{N}=14$; Female: $\mathrm{Y}=1, \mathrm{~N}=5$ ), and Non-smokers (Male: $\mathrm{Y}=0, \mathrm{~N}=21$; Female: $\mathrm{Y}=1, \mathrm{~N}=29$ ). This gave a Total $(Y=7, N=93)$. This shows that inhaling other peoples' smoke was not enjoyable so there is a general dislike in inhaling other peoples' smoke. 
Table 1: Mean rating for smokers and ex-smoker likes about smoking

\begin{tabular}{lcccc}
\hline \multicolumn{1}{c}{ Likes } & $\begin{array}{c}\text { Smokers } \\
\text { Mean }\end{array}$ & $\begin{array}{c}\text { Ex-smokers } \\
\text { Mean }\end{array}$ & $\begin{array}{c}\text { Overall } \\
\text { Mean }\end{array}$ & $\begin{array}{c}\text { Calculated } \\
\text { t-value }\end{array}$ \\
\hline Helps me relax & $2.97^{*}$ & 2.00 & $2.57^{*}$ & $2.223+$ \\
Lenjoy it & 2.10 & 1.50 & 2.27 & 1.470 \\
Helps me cope with stress & $2.62^{*}$ & 1.75 & 2.22 & 2.207 \\
Something to do when l am bored & 0.97 & 1.05 & 1.86 & 0.249 \\
Helps to break up my working time & 1.83 & 1.05 & 1.51 & 1.901 \\
Something to do with my friends and family & 2.45 & 1.90 & 1.41 & 1.239 \\
Nothing good & 1.52 & 1.25 & 1.39 & 0.709 \\
Stops me from putting on weight & 1.24 & 1.60 & 1.00 & 0.901 \\
\hline
\end{tabular}

"Major like for smoking (mean $=2.5$ ) $+=$ Significant at 0.05 level

Source: Okpala (2003)

Table I shows that most smokers like smoking because it 'helps them relax' (mean $=2.97$ ) and 'helps them cope with stress' (mean=2.62). More ex-smokers agreed that they liked smoking because it helped them relax than it helped them cope with stress. The major overall reason for liking smoking is because of its relaxation properties (mean $=2.57$ ). The t-test performed on the likes about smoking gave an overall $P$ value of
0.135627 , which shows $13 \%$ chance that the difference in mean occurred by chance. This means that the views of smokers and ex-smokers on why they like smoking are similar. The tvalue for the individual reasons shows that it is only on the reason 'Helps me to relax' that the rating of smokers and ex-smokers differ significantly. For smokers, smoking helps them to relax while for ex-smokers, it did not help.

Table 2: Mean ratings on dislikes about smoking

\begin{tabular}{|c|c|c|c|c|c|}
\hline Dislikes & Smokers & $\begin{array}{l}\text { Ex- } \\
\text { smokers }\end{array}$ & $\begin{array}{c}\text { Non- } \\
\text { smokers }\end{array}$ & $\begin{array}{l}\text { Overall } \\
\text { Mean }\end{array}$ & $\begin{array}{l}\text { Sign. of F } \\
\text { ANOVA }\end{array}$ \\
\hline $\begin{array}{l}\text { It is bad for my health and the health of } \\
\text { the people near me }\end{array}$ & $3.14^{*}$ & $3.70^{*}$ & $3.82 *$ & $3.60^{*}$ & $\therefore \quad 0.002+$ \\
\hline It is expensive & $3.10^{*}$ & $3.45^{*}$ & $3.10^{*}$ & $3.17^{*}$ & 0.519 \\
\hline Makes one less physically fit & $2.93^{*}$ & $3.30^{*}$ & $3.27^{*}$ & $3.18^{*}$ & 0.419 \\
\hline $\begin{array}{l}\text { Do not like feeling dependent on } \\
\text { cigarettes }\end{array}$ & 2.21 & $2.80^{*}$ & $2.92 *$ & $2.69^{\circ}$ & 0.117 \\
\hline Makes my clothes and breathe stink & $2.76^{*}$ & $3.30 *$ & $3.51 *$ & $3.25^{*}$ & $0.012+$ \\
\hline Bad example for children & $2.66^{*}$ & $2.95^{*}$ & $3.59^{*}$ & $3.19^{\circ}$ & $0.001+$ \\
\hline Unpleasant for people near me & $2.76^{*}$ & $3.10^{*}$ & $3.33^{*}$ & $3.12^{*}$ & 0.123 \\
\hline Bad for my health & 2.48 & $3.25^{*}$ & $2.92^{*}$ & $2.86^{\circ}$ & 0.141 \\
\hline $\begin{array}{l}\text { People around me disapprove of my } \\
\text { smoking }\end{array}$ & 1.72 & $2.75^{*}$ & 1.90 & 2.02 & $0.043+$ \\
\hline
\end{tabular}


Table 2 shows a general dislike for smoking. Smokers disagree that they 'do not like feeling dependent on cigarettes" (mean $=2.21$ ) which means that they like the dependency. They were also on the border on 'smoking being bad for the teeth' (mean $=2.48$ ) as they were not sure if it does, though ex-smokers agree that this does. Non-smokers and smokers disagree on the statement that "people around them disagree on their smoking' (mean=1.90 and 1.72 respectively). Non-smokers disagree because they do not smoke themselves. Smokers disagree because they probably smoke with other smokers and the non-smokers around do not mind their smoking. The one-way ANOVA performed on the overall mean ratings on dislike about smoking gave a $P$ value of 0.030285 . This value shows that there is a $3 \%$ chance that the differences in mean ratings obtained occurred by chance. This means that there is general dislike for smoking. A detailed item by item ANOVA also reveals four areas where differences in rating are significant: "It is bad for my health' and the health of the people near me; 'Makes my clothes and breath smell'; 'Bad example for children'; and 'people around me disapprove of my smoking'.

Table 3 explains the fact that the majority of smokers and ex-smokers enjoy smoking.

From Table 4 , the majority of smokers and exsmokers did not agree on any of the reasons for starting smoking. None of the reasons was rated $\geq 2.5$. But from the result, the highest means were 'curiosity reasons'; 'friends smoked and thought it cool'. 'Don't know' was the major that was answered by the smokers and exsmokers.

The two-way ANOVA performed on the means for reasons on starting smoking gave $P$ values of 0.114959 for gender, 0.5083 for smoker/exsmoker and 0.994354 for the interaction between gender and smoking status. This implies that there is an $11 \%$ probability that the differences in gender occurred by chance, a $51 \%$ probability that the differences for smoker/ex-smoker occurred by chance and a $99 \%$ likelihood that the differences in the interaction between gender and smoking status occurred by chance.

\section{DISCUSSION}

The discussion is in two parts, namely:

1. Likes and Dislikes of Smoking; and

2. Major Factors Prompting Smoking.

\section{Likes and Dislikes of Smoking}

From Table 1, starting with the likes about smoking, most of the smokers agreed that smoking helps them relax and helps them cope with stress as recorded in Marsh and Mathieson (1983). The majority of ex-smokers did not agree that smoking helped them relax and cope with stress. Helping them relax and helping them to cope with stress go hand in hand. Stress is any factor that threatens the health of the body or has an adverse effect on its functioning. Constant

Table 3: Smokers and Ex-smokers Views on Enjoying Smoking

\begin{tabular}{lcccc}
\hline \multicolumn{1}{c}{ Group } & Yes & $\begin{array}{c}\text { Percentage } \\
(\%)\end{array}$ & No & Percentage (\%) \\
\hline Male Smokers & 11 & 92 & 1 & 8 \\
Female Smokers & 17 & 100 & 0 & 0 \\
Male Ex-smokers & 8 & 57 & 6 & 43 \\
Female Ex-smokers & 5 & 83 & 1 & 17 \\
Total & 41 & 84 & 8 & 16 \\
\hline
\end{tabular}

Source: Okpala (2003) 
Table 4: Frequencies and Means on Reasons for Starting Smoking

\begin{tabular}{|c|c|c|c|c|c|c|c|c|c|c|c|c|}
\hline \multirow{3}{*}{ Reason } & \multirow{3}{*}{$S A$} & \multirow{3}{*}{$A$} & \multirow{3}{*}{$D$} & \multirow{3}{*}{$S D$} & \multirow{3}{*}{$D K$} & \multicolumn{2}{|c|}{$S(n=29)$} & \multicolumn{2}{|c|}{$E S(n=20)$} & \multicolumn{2}{|c|}{$S \& E S$} & \multirow{3}{*}{$\begin{array}{c}\text { Overall } \\
\text { Meant } \\
(N=49)\end{array}$} \\
\hline & & & & & & 12 & 17 & 14 & 6 & 26 & 23 & \\
\hline & & & & & & $\mathbf{M}$ & $\mathbf{F}$ & $\mathbf{M}$ & $\mathbf{F}$ & $\mathbf{M}$ & $F$ & \\
\hline $\begin{array}{l}\text { Friends all } \\
\text { smoked }\end{array}$ & 4 & 19 & 5 & 4 & 17 & 2.16 & 1.76 & 1.79 & 1.00 & 1.98 & 1.38 & 1.68 \\
\hline $\begin{array}{l}\text { Parents } \\
\text { smoked }\end{array}$ & 2 & 4 & 5 & 13 & 25 & 1.08 & 0.76 & 1.00 & 0.50 & 1.04 & 0.63 & 0.84 \\
\hline $\begin{array}{l}\text { Ilad own } \\
\text { money for } \\
\text { cigarettes }\end{array}$ & 2 & 6 & 5 & 9 & 27 & 1.00 & 0.82 & 1.00 & 0.83 & 1.00 & 0.83 & 0.92 \\
\hline $\begin{array}{l}\text { Thought it as } \\
\text { "cool" }\end{array}$ & 2 & 17 & 4 & 7 & 19 & 1.92 & 0.94 & 2.00 & 1.17 & 1.96 & 1.06 & 1.51 \\
\hline $\begin{array}{l}\text { Boyfriend/ } \\
\text { Girlfriend } \\
\text { smoked }\end{array}$ & 0 & 5 & 5 & 12 & 27 & 0.75 & 0.94 & 0.64 & 0.50 & 0.70 & 0.72 & 0.71 \\
\hline $\begin{array}{l}\text { Curiosity } \\
\text { reasons }\end{array}$ & 8 & 17 & 4 & 4 & 16 & 2.33 & 1.71 & 1.86 & 2.00 & 2.10 & 1.86 & 1.98 \\
\hline
\end{tabular}

Key: SA-Strongly Agree. A-Agree, D-Disagree, SD-Strongly Disagree, DK-Don't Know, S-Smoker, LS- Ex-smoker, M-Male, F-Fenale.

Source: Okpala (2003)

stress brings about changes in the hormonal body balance (Oxford Reference Concise Medical Dictionary, 1994). The nicotine, in cigarette when smoked, gets into the blood and produces a pleasant sensation on reaching the brain. Nicotine binds to the nicotinic receptors located on noradrenalin-secreting neurons and these nellrons are desensitized by the nicotine concentration similar to that found in the plasma of many smokers. This may contribute to the 'tranquilizing' properties of tobacco smoke which is, most of the time, reported by smokers exposed to stress factors (Balfour and Fagerstrom, 1996). This 'tranquilizing' property is what brings about relaxation in those people who smoke.

Smokers and ex-smokers on the whole, disagreed (Table 1) on the 'liking smoking because they enjoy it', 'something to do when bored' and 'helping to break up working time'. The overall agreement is only for 'Helps me to relax'. Yet, very few agreed that there was nothing good to like about smoking. The t-test performed on the likes about smoking showed that there is no significant difference between the responses obtained from smokers and ex-smokers. This means that smokers and ex-smokers like smoking for the same reasons. The majority of smokers enjoy smoking and some of the ex-smokers did enjoy smoking (Table 3 ). In total, $84 \%$ of the subjects enjoy smoking.

Almost all the subjects (93\%) did not like inhaling other people's smoke. This shows that even though many of them like inhaling and exhaling smoke from a burning cigarette, they do not like inhaling the smoke, which someone else has exhaled. This was expected because the effect obtained when inhaling the thick smoke from a burning cigarette would not be the same as in- 
haling the smoke exhaled by other people.

On the whole, all subjects agreed that they dislike smoking. The subjects agreed that they dislike smoking because it is bad for their health, bad for the health of people near them, it is expensive, it makes one less physically fit, it makes their breath and clothes smell, it is a bad example for children and unpleasant for people around them (Table 2). Most smokers like feeling dependent on cigarettes but ex-smokers do not like feeling dependent on cigarettes. Nonsmokers agreed that they do not like feeling dependent on cigarette even though they do not smoke. Ex-smokers and non-smokers also agree that smoking is bad for their teeth but smokers disagree. Only ex-smokers agreed that they dislike smoking because people around them disapproved of their smoking. Smokers disagreed because they smoke with other smokers or smoke by themselves. Non-smokers disagree as they do not smoke at all and so they would not really know if people disapproved of their smoking. The t-test performed on students dislikes about smoking showed that there is a significant difference in the responses by smokers, exsmokers and non-smokers. This implies that the views of non-smokers would be different from those that smoke as well as those who have smoked and vice versa. Non-smokers will dislike some aspects of smoking but not all.

Two-way Analysis of Variance (ANOVA) gave no significant difference between males and females, smokers and ex-smokers and no significant interaction between gender and being a smoker/ex-smoker. This means that smoking was started for the same reasons irrespective of their gender or smoking status. So the reasons given by a male smoker would be the same or similar to the reasons given by a female exsmoker and same with other combinations of gender and smoking status. But on a closer look at the $P$ values for gender, smoking status and interaction, the value for the gender is less than the others. This could mean that there is chance that with a large number of subjects, there could be a significant difference been one of the main influences on the students picking up habits. This factor was also identified in a study carried out at the Abha branch of the King Saud University in Saudi Arabia (www.kfshrc.edu.sa/annals/ 183/97-279.html). The saying 'curiosity kills the cat' is heard ever too often and in this case, starting smoking because of curiosity is a step towards ill-health. It has been said that smoking is the single greatest cause of preventable disease and premature death in United Kingdom (Callum, 1998) and the world, but still, students and young still engage in smoking.

From their views, which have been extensively studied, students know that smoking is very bad and dangerous to their health and they do know that stopping smoking will improve their health. but once they are hooked on it, it is very hard to quit. The consequences of smoking would not materialize now or in the next five years but in the twenty to thirty years time when the body is becoming tired and weary.

\section{CONCLUSION}

This study confirms the 'Tranquilizing' properties of tobacco smoke as reported by smokers exposed to stress factors (Balfour and Fagerstrom, 1996). It brings about relaxation in those people who smoke. The majority of smokers enjoy smoking and some of the ex-smokers did enjoy smoking. Almost all the subjects $(93 \%)$ did not like inhaling other people's smoke. On the whole, all subjects agreed that they dislike smoking. The overall mean of subjects that agreed they dislike smoking followed trend: It is bad for my health and the health of the people near me>Makes their breath and clothes smell> Bad example for children > Makes one less physically fit $>$ It is expensive $>$ Unpleasant for people around them $>$ It is bad for their teeth $>$ Do not like feeling dependent on cigarettes. Though the views of non-smokers differ from those that smoke as well as ex-smokers, and vice versa, there is general dislike for smoking and inhaling other peoples' smoke. Majority of 
smokers and ex-smokers enjoy smoking.

Major reasons for starting smoking deduced the trend: Curiosity reasons >Friends smoked Thought it as "cool'; >though the majority did not agree to this. Few subjects agreed that they started smoking because their parent smoked, had money to buy cigarettes and their girifriend / boyfriend smoked. The $P$ values for gender, smoking status and interaction, have the value for the gender less than the others. This could mean that there is chance that with a large number of subjects, there could be a significant difference been one of the main influences on the students picking up habits.

Students know that smoking is very bad and dangerous to their health and they do know that stopping smoking will improve their health, but once they are hooked on it. it is very hard to quit. The consequences of smoking would not materialize now or in the next five years but in the twenty to thirty years time when the body is becoming tired and weary. This study will be invaluable to the public, school guidance counselors, researchers, and medical personnel. including pharmacists to assist in problem-solving issues of cigarette smoking.

\section{ACKNOWLEDGEMENT}

The author expresses gratitude to Dr. Frank Radcliffe and Dr. Paul Gard of University of Brighton School of Pharmacy and Biomolecular Sciences, UK. Also, he is grateful to widowed mother and scholar, Prof. Dr. Julie Okpala of the University of Nigeria Nsukka (Nigeria) and younger brother, Mr. Odili Okpala of Faculty of Agriculture, Kwame Nkrumah University of Science and Technology. Kumasi (Ghana); for their critics, contribution and review of scripts.

\section{REFERENCES}

Balfour, D.J.K. and Fagerstrom, K.O. (1996). Pharmacology of nicotine and its uses in smoking cessation and neurogenerative disorders. Pharmacol. Therap., 76, 51-81.

Callum, C. (1998). The UK smoking epidemic: deaths in 1995. London: Health Education Authority.

Department of Health (1998). Smoking Kills: A White Paper on Tobacco. London: The Stationary Office, 9.

Employment and Social Security, Health and Safety linspectorate, Passive Smoking at Work, Health and Safety Guidance, Available URL www ess.gov.je/his/brochures/ passive smoking/default.asp? URL $=$ what is PS.html [Accessed 10 March 2003]

Middleton. M. R. (2004). Data Analysis Using Microsofi Excel Updated for Office XP, $3^{\text {rt }}$ Edition, Canada: Thomson Brooks and Cole.

Marsh, A. and Mathieson, J. (1983). Smoking Attindes and Behaviour, London: HMSO

Okpala, U. (2003). Students" Attitudes Towards Smoking. Unpublished M.Pharm Dissertation, School of Pharmacy and Biomolecular Sciences, University of Brighton.

Okpala. U. (2006). Cigarette smoking and habits (1): some studies on gender and smoking patterns among university of Brighton business students (accepted for publication in the Journal of Science and Technology).

Oxford Reference Concise Medical Dictionary (1994). $4^{\text {th }}$ Edition. Oxford: Oxford University Press.

Smoking habits of King Satd University Students in Abha, Sandi Arabia, Available URL, www.kfshre.edu.sa/annals/183/97-27279. html [Accessed 20 April. 2003]. 